\title{
DIREITO INTERNACIONAL E CARANA
}

\author{
Renan Moreira Jaqueira ${ }^{1}$
}

\begin{abstract}
Resumo
"Direito Internacional e Carana" tem como objetivo analisar considerações de direito internacional público relevantes para um representante de Estado em uma reunião no Conselho de Segurança. O artigo visa, a partir de um caso hipotético, trabalhar questões encontradas no dia a dia dos tomadores de decisão, os quais precisam pensar em fatores legais e políticos para buscar uma solução que possa ser efetivamente apresentada. Assim, o artigo examina questões como: (i) um arcabouço básico jurídico para compreensão do que são fontes de direito internacional e como elas se relacionam; (ii) a centralidade do uso da força no direito internacional exercida na figura do Conselho de Segurança; e (iii) a prerrogativa de veto dos membros permanentes do Conselho de Segurança, a fim de fazer uma ambientação de como o Conselho de Segurança se encaixa nesse cenário do direito internacional público de modo a permitir uma solução para o caso.
\end{abstract}

Palavras-chave:Direito Internacional Público -Fontes de Direito Internacional - Uso da Força -Conselho de Segurança

\begin{abstract}
"International Law and Carana" tries to analyze issues of the international public law that may seem relevant to a representative of state in a Security Council meeting. Based on a hypothetical case developed for this purpose, the article aims at working on problems faced on a daily basis by decision makers, who need to take into account both legal and political factors in order to find a solution that can effectively be presented. Therefore, it examines issues such as: (i) a basic legal framework for the comprehension of what are sources of international law and how they relate to each other; (ii) the centrality of the use of force in international law exercised by the Security Council; and (iii) the veto power of the permanent members of the Security Council, in order to show how the Security Council relates to the international public law and together they may indicate an answer to the issue.
\end{abstract}

Keywords: International Law - Sources of International Law - Use of Force - Security Council

\footnotetext{
${ }^{1}$ Bacharel em Relações Internacionais pela Pontifícia Universidade Católica do Rio de Janeiro e bacharel em Direito pela Universidade Federal do Rio de Janeiro com diplomação cum laude. Ganhador do prêmio Gerson Moura pelo melhor trabalho de conclusão no eixo de conflitos no ano de 2013, na PUC-Rio. Email: dr.renanmoreira@gmail.com
} 


\section{Introdução}

\section{a) Proposta do Trabalho}

O presente artigo foi desenvolvido a partir de um trabalho de conclusão de curso. Para a tarefa, o professor-orientador trouxe o caso de um país fictício, chamado Carana, que tem vários problemas tipicamente discutidos nas relações internacionais. Para os fins da análise, considerar-se-á que o país é membro da Organização das Nações Unidas, tendo assinado todos os tratados internacionais da organização sem qualquer restrição.

No momento do estudo, os acontecimentos no país atingiram grandes proporções, de modo que foi convocada uma reunião do Conselho de Segurança para tratar de possíveis medidas a respeito do que ocorreu recentemente em Carana.

A proposta é traçar um panorama geral do que acontece no país em pauta, pensar em repercussões no sistema internacional que sejam relevantes para um representante de Estado no Conselho de Segurança, assim como recomendações a esse representante que terá uma reunião no Conselho nos próximos dias.

Este artigo é baseado em um trabalho de curso com um conceito mais prático do que acadêmico em si. Por isso, não se trata de uma proposta com análise metodológica e teórica específica, pois o objetivo original era elaborar um breve relatório que ajudasse na ambientação de alguém que fosse, na prática, representar seu país no Conselho de Segurança das Nações Unidas.

Se, por um lado, as correntes teóricas e a metodologia ajudam-nos a entender e a analisar, por outro lado, um relatório prático busca respostas e soluções de uma maneira mais simplificada. Deste modo, o objetivo deste artigo não é apresentar exaustivamente e qualitativamente todos os meios possíveis de soluções de conflito ou de proteção de civis, mas apenas trazer uma visão que contribua para a discussão a partir de uma outra dimensão.

Mais especificamente para o caso, foi escolhido demonstrar como determinados elementos do direito internacional público incidem sobre a resolução de conflitos. Tendo em vista que o tema é o Conselho de Segurança, o autor escolheu tratar das fontes e da hierarquia destas no direito internacional público devido à importância desses elementos para a compreensão da centralidade do Conselho de Segurança no assunto.

\section{b) Ambientação}


Os recentes acontecimentos em Carana tiveram um impacto significativo na comunidade internacional, que enxerga com preocupação o futuro do Estado. Com a convocação de uma reunião do Conselho de Segurança da Organização das Nações Unidas, o Brasil, que é um dos membros não permanentes nesse momento, enviará um representante, o qual pede consultoria a respeito do direito internacional para uma participação mais bem informada na reunião.

Com relação aos bastidores políticos, junto dessa convocação, foi recebida a notícia também de que um dos membros permanentes indica estar preparado para tomar ações militares, com ou sem o aval do Conselho de Segurança para prevenir o que ele descreve como genocídio. Enquanto isso, um membro permanente do Conselho de Segurança indica que provavelmente irá vetar qualquer autorização fundamentada no capítulo VII da Carta das Nações Unidas.

Dentro desse ambiente, busca-se trazer questões a respeito do direito internacional auxiliando o diplomata brasileiro, que venha a representar o Brasil no Conselho de Segurança.

\section{Um Breve Histórico da República de Carana}

A República de Carana possui uma população dividida em três etnias predominantes: Kori, Falin e Tatsi. O convívio das três etnias é conturbado e se torna, muitas vezes, fruto de conflitos no país. Além de estarem espalhados por todo o território nacional implicando em tensões habituais entre as etnias em diversos locais, ainda existem fatores externos que corroboram para o acontecimento dessas disputas. Por conta de questões sazonais e de mudanças climáticas, o deslocamento interno de grupos étnicos se mostra outra fonte de desentendimento no país.

O país se tornou independente em 1962, e teve um líder Falin - que é a maioria étnica do país com 49\% - suprimindo todos os partidos políticos que não o seu. Com um grande descontentamento popular amplificado com a situação econômica instável do país e ainda com problemas de corrupção e ineficiência, a república sofreu diversos golpes militares até conseguir finalmente, sob pressão internacional, eleger o seu primeiro presidente em 1986: Jackson Ogavo (PDC - Partido Democrático de Carana). Conduzindo um governo democrático e tentando dar representatividade para as etnias, apesar de ainda apresentar maioria Falin, foi elaborada a constituição consagrando princípios democráticosem 1991.Todavia,ocenáriovai se modificando com uma crescente corrupção e ineficiência 
econômica novamente, e a volta da repressão de representatividade de grupos étnicos, fragilizando desde 1998 cada vez mais a situação do país. Na prática, o único partido legalizado é o PDC, apesar de todo o teor constitucional político-democrático.

Desde 2000, dentro de toda essa disputa étnica cada vez mais acirrada, surgiram dois grupos rebeldes. O Movimento Patriótico de Carana (MPC), que vem tentando dominar a região oeste do país, é composto principalmente pela etnia Kori. Enquanto as Forças de Defesa de Carana (FDC) lidavam com a rebelião do MPC, surge um novo grupo no sul, composto principalmente pela etnia Tatsi, reunindo grupos rebeldes esparsos em um único movimento chamado ICSC - Combatentes Independentes do Sul de Carana.

O passado colonial de Carana fez com que suas fronteiras fossem artificiais, não representando as distribuições étnicas da região. Dessa forma, as etnias são compartilhadas com alguns dos países vizinhos. O país ao norte, o Estado independente de Sumora, tem uma população com 10\% da etnia Falin. Já o Estado independente de Katasi, a oeste, tem 38\% de sua população Kori. E os Tatsis representam $45 \%$ da população do Estado independente de Rimosa, localizado ao sul de Carana. Alguns desses países são acusados de apoiar grupos rebeldes em Carana, e lutas étnicas transbordam as fronteiras do país.

O Conselho de Segurança das Nações Unidas, por meio da Resolução no 1.844/2009, estabeleceu a Missão de Assistência das Nações Unidas em Carana (UNAC) para auxiliar na manutenção da lei e da ordem baseando-se no capítulo VII da Carta das Nações Unidas. A resolução também previu que a missão estabelecida deveria ajudar na implementação de um cessar-fogo entre as diferentes forças do país, reconhecido como Acordo de Paz de Kalari (KPA - Kalari Peace Agreement).

Dentro desse histórico, deve-se ressaltar ainda que a República de Carana passa por sérios problemas internos de diversas naturezas. Esses problemas incluem questões de direitos humanos como acusações de torturas, execuções, violência étnica, escravidão sexual, mutilação genital feminina, estupros, entre outros. A economia do país não consegue se manter estável. O sistema político do país apresenta um quadro de corrupção grave e é considerado bastante ineficiente. A população tem ainda problemas de fome e segurança. Tudo isso torna o ambiente de Carana bastante complexo e conflituoso.

\section{a) Acontecimentos Recentes}


Eventos recentes tumultuam a República de Carana e os debates internacionais acerca da região. Em uma tentativa de conciliar os desentendimentos entre MPC e PDC, foi programada uma reunião entre o atual primeiro ministro de Carana - Sr. Lucien Langata - e o presidente de Katasi - Sr. Em -, supostamente aliado ao MPC. Contudo, ambos acabaram mortos em um ataque de um suicida. Sem que nenhum grupo rebelde local tenha reivindicado o ataque, e tendo sido encontrada uma bandeira do MPC nos destroços, o governo passa a assumir uma ofensiva contra o MPC situado no oeste.

O governo que vinha tomando atitudes nacionalistas e étnicas, repreendendo outras etnias que não a Falin, passa a defender a ideia de Carana como uma nação dos Falin. Na capital, Sr. Ogavo tomou o poder com a Guarda Presidencial e, ao tentarem aprisionar líderes do MPC que estavam na capital, dois acabaram mortos por supostamente terem resistido à prisão. Contudo, um diretor de inteligência do MPC conseguiu fugir e anunciou no rádio o reinicio do conflito. O MPC, em resposta, passou a avançar para a capital Galasi com tanques e arsenal que foram conseguidos no caminho. Deve-se ressaltar ainda que os barcos usados pelo MPC em sua operação ofensiva, descrita acima, estavam com os símbolos da marinha de Katasi.

Ainda em Galasi, staffs da UNAC foram mortos durante um ataque a Tatsis deslocados internamente vindos do Sul, e tiveram seus corpos esquartejados e arrastados nas ruas da capital. O país de onde os staffs mortos vieram retirou suas tropas, pois seria inviável a permanência de uma missão de paz onde a insegurança atinge níveis inconcebíveis. Em todo o país, foram reportados ataques às etnias Kori e Tatsi, o que foi declarado pelo país contribuinte da UNAC como um antigo ódio étnico. Vários protestos pelo país clamavam pela saída da missão da ONU.

Enquanto isso, Sumora acusou Katasi e Rimosa de estarem agindo de forma agressiva contra o governo de Carana e mobilizou suas forças armadas se disponibilizando a auxiliar o governo do Sr. Ogavo a defender a Capital. Além disso, no Sul, o governo de Rimosa lançou uma ofensiva invadindo o Sul de Carana para combater o grupo ICSC que supostamente estaria ligado ao grupo rebelde (ELF - Elassasonian Liberation Front) existente no norte de Rimosa.

\section{O Direito Internacional}

\section{a) O Cenário Internacional}


No Direito Internacional, os problemas devem ser analisados dentro da conjuntura em que ele está inserido, considerando que, no âmbito internacional, não existe uma entidade que exerça um controle sobre todos os Estados, ou seja, não existe um ente superior ao Estado. A anarquia internacional, portanto, é um dos fatores essenciais para se entender essa especificidade do direito internacional. Ao contrário de um direito doméstico, não existe um ator que tenha o poder e a legitimidade de impor uma lei universal. Odireitointernacionalpossuisuasfontesbaseadasnasdecisões coletivas dos Estados nessa área internacional (Çali, 2010, p. 5-7).

Essa falta de um ente acima que comande não significa, contudo, que não existam influências dentro do sistema. Essa anarquia deve ser entendida como a ausência de alguma autoridade superior legítima que dê ordens, não entrando na discussão acerca das diferentes capacidades ou poderes que os Estados têm de agir perante uns aos outros. Segundo as lições de Chris Brown e Kirsten Ainley: "Sovereign states are sovereign because no higher body has the right to issue orders to them. In practice, some states may have the ability to influence the behaviour of other states, but this influence is a matter of power not authority"(Brown; Ainley, 2009, p.3).

Podemos perceber que o entendimento predominante é de que os Estados são soberanos, e essa soberania possui duas principais características: uma no âmbito interno e outra no âmbito externo. Para o âmbito externo, a soberania implica que todos os Estados são iguais um perante o outro, de forma que cada um tem o domínio de um determinado território e sozinho deve ele administrar sem a intervenção de terceiros. No âmbitointerno,entendesequeoEstadoéúnicoequeeleéoenteresponsávelpor prezar pelo seu território incluindo aqueles que lá habitam (DELGADO, 2006, p. 61-69).

Dentro desse cenário, surgiu a Organização das Nações Unidas como uma organização internacional com o objetivo de tentar ajudar na coordenação da relação entre esses Estados soberanos de forma a tornar o seu convívio mais harmonioso e pacífico. Os Estados têm o ideal de se reunir nesta organização para poder tentar trazer mais legitimidade para as suas ações e ter um relacionamento mais transparente e sociável junto à comunidade internacional (BROWNLIE, 2008, p.738).

\section{b) As Fontes}


Considerando a ausência de um legislador internacional, existe um entendimento comum e doutrinário de que no artigo 38 do Estatuto da Corte Internacional de Justiça está elencado o rol das principais fontes de direito internacional. O Estatuto enumera:

\begin{abstract}
"Article 38
1. The Court, whose function is to decide in accordance with international law such disputes as are submitted to it, shall apply:

a. international conventions, whether general or particular, establishing rules expressly recognized by the contesting states;

b. international custom, as evidence of a general practice accepted as law;

c. the general principles of law recognized by civilized nations;

d. subject to the provisions of Article 59, judicial decisions and the teachings of the most highly qualified publicists of the various nations, as subsidiary means for the determination of rules of law." (Statute of the International Court of Justice, 2013, p. 26)
\end{abstract}

O próprio artigo do Estatuto declara que as fontes enumeradas no item (d) são formas subsidiárias para as determinações legais. Essas fontes existem como auxiliares para a aplicação do direito, mas não trazem um valor legal próprio. As doutrinas e as decisões judiciais são mais utilizadas no sentido de auxiliar na interpretação e entendimento das normas. ${ }^{2}$ Deste modo, as principais fontes de direito internacional são as convenções e os tratados internacionais firmados entre os Estados, o costume e os princípios gerais de direito. ${ }^{3}$ Assim, comosintetiza Hugh Thirlway:

\footnotetext{
"Treaties are binding only on the parties to them; custom (which pre-supposes an established practice and a psychological element known as the opinion juris) is in principle binding on all States, unless it is a 'special' or 'local' custom, and save for the exceptional case of the 'persistent objector'. The general principles of law (as evidenced by national legal systems) may be appealed to if a point is not settled either by treaty or custom." (THIRLWAY, 2010, p. 95).
}

Como já pode ser notado no texto acima, parte da doutrina defende a existência de uma suposta hierarquia entre essas fontes de direito. Essa relação é discutida na literatura e gera diversos questionamentos quanto às suas aplicações.

\footnotetext{
2 Existe uma classificação de fontes, sendo elas formais ou materiais. As fontes formais conteriam a norma em si, enquanto que as fontes materiais seriam documentos em que os termos da norma é explicitada. Assim, os três primeiros itens seriam fontes formais propriamente ditas, enquanto que o último item seria uma fonte material de direito. Para mais: THIRLWAY, Hugh. The Sources of International Law. In: EVANS, Malcolm D. International Law. $3^{\mathrm{a}}$ ed. New York: Oxford University Press Inc., 2010, p. 110.

3 Existem discussões doutrinárias acerca da existência de outras fontes de direito internacional. O questionamento seria a respeito do artigo do Estatuto da Corte Internacional de Justiça ser ou não exaustivo. Dessa forma, existem outras fontes que seriam aceitas em determinados casos, mas não seriam propriamente principais dentro do ordenamento internacional. Dentre as possíveis outras fontes de direito internacional encontram-se: Atos unilaterais, Analogia e equidade, Decisões de Organizações Internacionais, jus cogens e soft law, por exemplo.
} 


\section{c) A Hierarquia}

Percebe-se que os princípios gerais de direito, exatamente pela sua natureza principiológica, possuem um caráter mais geral. Os princípios normalmente devem ser interpretados como diretrizes a serem seguidas devendo ajudar na interpretação das normas, mas também podem ser aplicados diretamente. Em um eventual conflito entre princípios, utiliza-se a ponderação como forma de resolução, em que um princípio é afastado e o outro é aplicado. Contudo, a aplicação de um não revoga o outro, eles são simplesmente verificados casuisticamente (ALEXY, 1985, p.75). Assim, dentro de uma possível hierarquia das fontes do direito internacional, parte da doutrina vai entender que os princípios gerais de direito serviriam de maneira subsidiária, só sendo utilizados quandonão houver um tratado ou um costume já pré-estabelecido para o caso.

No que tange a hierarquia entre o tratado internacional e o costume, a aplicação destes dependerá do caso em si. Inclusive, há casos em que o tratado internacional consolida de forma material um costume ou em que um costume surge com a negociação de um tratado. Deve-se observar, no entanto, que a materialidade de um tratado torna a sua aplicação relativamente mais fácil e direta. Já um costume, por ter um caráter mais abstrato, sendo ele um hábito ou uma prática, por exemplo, é relativamente mais difícil de ser comprovado ou evidenciado. Pela sua característica de ser aplicado, em geral, a todos, o costume deve ser amplamente praticado e concordado, sendo mais difícil a sua comprovação. Entretanto, não existe ao certo uma confirmação absoluta de que o tratado ou o costume teriam uma aplicação mais importante e primária que o outro (MAZZUOLI, 2011, p. 121).

Como explica a Corte Internacional de Justiça no caso Nicaraguavs USA, mesmo que um tratado venha a regular matéria já praticada em costume internacional, isso não extingue o costume em si.

\footnotetext{
"The Court found that this identity of content in treaty law and in customary international law did not exist in the case of the rule invoked, which appeared in one article of the treaty, but did not suggest that such identity was debarred as a matter of principle : on the contrary, it considered it to be clear that certain other articles of the treaty in question "were ... regarded as reflecting, or as crystallizing, received or at least emergent rules of customary international law" (I.C.J. Reports 1969, p. 39, para. 63). More generally, there are no grounds for holding that when customary international law is comprised of rules identical to those of treaty law, the latter "supervenes" the former, so that the customary international law has no further existence of its own. "(I.C.J. Reports, 1986, p. 95)
} 
Outra questão abordada pela doutrina é quanto ao aparente conflito de normas. Existem dois brocados do direito que ajudam a dirimir qual norma aplicar diante de um conflito aparente de normas. A expressão "lex posterior derogat priori" vem do pensamento de que se as partes que convencionam aquela norma quiseram estabelecer e aceitar uma nova norma no tempo, o que significa que elas abdicaram da anterior para vigorar a seguinte. Desta maneira, aplicando ao direito internacional, em um conflito entre tratados ou costumes, por exemplo, de tempos distintos, aplica-se o que fora promulgado ou praticado por último, pois as partes, ao aceitarem esse novo tratado ou costume, teriam subentendido que os anteriores teriam sido revogados tacitamente (THIRLWAY, 2010, p. 113-114).

Além disso, existe também a expressão "lex specialis derogat legi generali" em que a lei especial prevaleceria diante de uma lei geral. Isto se dá pela ideia de que quando duas partes decidem estabelecer uma lei mais específica, sabendo da existência de uma lei mais geral, significa que elas convencionaram que, naquela exceção, determinada norma deveria ser aplicada, e não a lei geral (THIRLWAY, 2010, p. 113-114).

\section{O Direito Internacional e Carana}

A Carta das Nações Unidas é o tratado internacional assinado e ratificado por quase todos os Estados do mundo. O sistema das Nações Unidas é considerado o mais abrangente no sistema internacional, de modo que muitas das discussões se passam dentro dessa organização que foi criada para ajudar na comunicação e no entendimento entre os países do mundo. E, tendo essa organização sua origem formal em um tratado internacional escrito, assinado e ratificado pela maioria dos países, isso só amplia a legitimidade de atuação da organização em si e de tudo que ocorre dentro de seu âmbito.

A República de Carana assinou e ratificou a Carta das Nações Unidas fazendo com que o Estado faça parte da Organização das Nações Unidas (ONU) e, consequentemente, esteja submetido às previsões da organização. Sendo a Carta um tratado internacional propriamente dito, ela se configura como uma fonte que pode ser analisada dentro de uma perspectiva de aplicação do direito internacional aos incidentes de Carana.

Existem dois principais aspectos que devem ser considerados por um representante de um Estado membro do Conselho de Segurança, de acordo com os rumores políticos. O primeiro deles é a intenção de um membro utilizar ações militares, com ou sem o aval do Conselho de Segurança, para impedir o que acredita ser uma violação grave de direitos 
humanos. O segundo deles é que um membro permanente tenha mostrado fortes inclinações a utilizar sua prerrogativa de veto em qualquer resolução cujo fundamento seja o capítulo VII da Carta das Nações Unidas.

Como ponto de partida para a análise, é necessário ressaltar que, em regra, existe uma proibição do uso da força de acordo com a citada Carta.

\footnotetext{
“ARTIGO 2 - A Organização e seus Membros, para a realização dos propósitos mencionados no Artigo 1, agirão de acordo com os seguintes Princípios:

(...)

3. Todos os Membros deverão resolver suas controvérsias internacionais por meios pacíficos, de modo que não sejam ameaçadas a paz, a segurança e a justiça internacionais.

4. Todos os Membros deverão evitar em suas relações internacionais a ameaça ou o uso da força contra a integridade territorial ou a independência política de qualquer Estado, ou qualquer outra ação incompatível com os Propósitos das Nações Unidas." (SALIBA, 2008, p. 716)
}

Percebe-se que, no artigo segundo, a evidente proibição da força elencada na norma traz ainda dois elementos mais específicos que são a integridade territorial e a independência política. Em uma visão restritiva e reducionista do dispositivo, interpretar-se-ia que não é permitido o uso da força apenas quando há violação desses dois elementos dos Estados. O problema dessa visão é que ela esvazia o caráter técnico-legal e passa a ter um aspecto político, que aumenta a possibilidade de abrangência das supostas "exceções", o que daria margem ao abuso do direito. Na visão de Başak Çali, não há dúvida quanto a momentos em que intervenções para salvar vidas seriam necessárias. Porém, ele afirma que Estados não atuam com um único propósito, o que torna tudo mais complexo.

\footnotetext{
"This means that no one really denies that there could be circumstances where innocent lives can only be saved by outside intervention. The central problem is that states do not act with a single motivation when they decide to use force and realtime interventions with mixed motivations are prone to cause more suffering than they may end, and set in motion bigger armed conflicts." (ÇALI, 2010, p. 223224)
}

Contudo, toda a ratio da Carta das Nações Unidas é voltada para a proteção da soberania e da independência de seus Estados tanto quanto para a harmonia e a segurança do ambiente internacional, de modo que essa interpretação limitadora iria contra o restante do que o tratado tenta proteger. Segundo Spencer Zifcak, as negociações do tratado mostram que a verdadeira proteção buscada pelo dispositivo era não somente para a integridade territorial e para a independência política, mas para os Estados em sua totalidade. Assim o que prevaleceria, seria uma compreensão de que a norma abriga qualquer tipo intervenção e não só apenas aqueles contra a integridade territorial ou independência política. 


\begin{abstract}
"Such an interpretation faces great difficulty, however, because it creates the prospect of a damaging ambiguity in the Charter's interpretation. Even a brief look at the travauxpreparatoire, as a means of resolving such an ambiguity, demonstrates clearly that such an adventurous interpretation of the qualification has little if any plausible foundation. Instead, the original aim of the non-intervention principle appears to have been to protect smaller States and the words 'territorial integrity and political independence' were added as supplements to, not as detractions from, the general prohibition on the use of force. "(ZIFCAK, 2010, p. 506)
\end{abstract}

No caso de Carana, mais especificamente, percebe-se que houve a transgressão das fronteiras do país. Dessa forma, já fica evidente a necessidade de alguma resposta por parte da ONU. Mesmo que não houvesse outros problemas relacionados ao conflito na região, a invasão do país já demonstra a obrigação da ONU de, pelo menos, se manifestar a respeito. A invasão do sul de Carana por parte das tropas de Rimosa já demonstra que qualquer conflito existente em Carana, mesmo que antes tenha sido considerado apenas interno, tomou proporções internacionais ao ser um conflito que engloba mais de um Estado soberano independente.

Como explicitado anteriormente, as decisões judiciais e doutrinas internacionais não são propriamente as principais fontes de direito internacional, contudo, elas contribuem para tentar ajudar na interpretação e no entendimento de outras previsões. O caso Corfu Channel submetido à Corte Internacional de Justiça, Reino Unido vs Albânia, teve diversos aspectos relevantes abordados. A corte decidiu que a Albânia deveria ser considerada responsável pelas explosões que ocorreram em seu espaço territorial litorâneo, resultando na morte de cidadãos do Reino Unido (International Court of Justice, 1949). Para o incidente apontado, pode-se ressaltar um trecho da decisão que ajuda a entender o peso da invasão do território de outro Estado.

\footnotetext{
"Between independent States, respect for territorial sovereignty is an essential foundation of international relations. The Court recognizes that the Albanian Government's complete failure to carry out its duties after the explosions, and the dilatory nature of its diplomatic notes, are extenuating circumstances for the action of the United Kingdom Government. But to ensure respect for international law, of which it is the organ, the Court must declare that the action of the British Navy constituted a violation of Albanian sovereignty."(ICJ Decision, 1949)
}

Tendo em vista que a ONU foi criada com o objetivo de harmonizar as relações internacionais melhorando o entendimento e criando um canal multilateral entre os Estados, um de seus principais objetivos é ajudar na manutenção da paz e da segurança internacional (SALIBA, 2008, p. 715).Para isso, o Conselho de Segurança (um dos principais órgãos da 
ONU) é encarregado de tomar decisões acerca de medidas a serem aplicadas, caso haja uma ruptura da paz ou um ato de agressão.

A Carta das Nações Unidas trata, em seu capítulo V especificamente, do Conselho de Segurança, abordando assuntos como procedimentos internos e questões gerais a respeito de votações no organismo, por exemplo. Dentre os tópicos do capítulo, um dos mais importantes diz respeito aos membros permanentes e à votação. $\mathrm{O}$ art. 23 explicita que o Conselho de Segurança será formado por 15 membros, dos quais 5 são permanentes. E, no art. 27, o tratado resguarda que as decisões precisarão do voto afirmativo de pelo menos 9 membros, inclusive de todos os membros permanentes. Da combinação desses dois dispositivos, depreende-se o chamado poder de veto dos membros permanentes, pois o seu veto implicaria no impedimento de qualquer resolução. ${ }^{4}$

Nota-se, então, que os rumores do membro permanente vetar uma resolução baseada no capítulo VII implicaria em todas as negociações acabarem sendo em vão, pois se apenas um membro permanente vetar, já é suficiente para que a resolução não seja aprovada. Isso demonstra o poder que esses 5 membros permanentes têm sobre as medidas que podem ser tomadas no cenário internacional, considerando que o Conselho de Segurança é o órgão legal para tomar medidas no que diz respeito à segurança e à paz internacional. Logo, qualquer negociação que vá seguir, precisa levar em consideração que não deverá ser muito incisiva, pois implica em um grande risco dela não passar pelo crivo do membro permanente, e, logo, do quórum exigido pelo tratado.

\section{"Capítulo V \\ CONSELHO DE SEGURANÇA \\ COMPOSIÇÃO \\ Artigo 23}

1. O Conselho de Segurança será composto de quinze Membros das Nações Unidas. A República da China, a França, a União das Repúblicas Socialistas Soviéticas, o Reino Unido da Grã-Bretanha e Irlanda do Norte e os Estados Unidos da América serão membros permanentes do Conselho de Segurança. A Assembléia Geral elegerá dez outros Membros das Nações Unidas para Membros não permanentes do Conselho de Segurança, tendo especialmente em vista, em primeiro lugar, a contribuição dos Membros das Nações Unidas para a manutenção da paz e da segurança internacionais e para os outros propósitos da Organização e também a distribuição geográfica eqüitativa.

(...)

VOTAÇÃO

Artigos 27

(...)

\footnotetext{
${ }^{4}$ Ressalta-se que, inicialmente, o entendimento majoritário era de que os membros permanentes sequer poderiam se abster, pois o tratado exige uma posição efetivamente afirmativa de todos os membros permanentes para a aprovação de uma resolução. Entretanto, posteriormente, o desgaste político de ter de vetar fez com que houvesse uma mudança na compreensão do dispositivo e o Conselho de Segurança passou a adotar uma interpretação a partir da ratio da norma, em que apenas quando um membro permanente efetivamente veta uma resolução é que ele demonstra que não quer que aquela resolução prospere.
} 
3. As decisões do Conselho de Segurança, em todos os outros assuntos, serão tomadas pelo voto afirmativo de nove membros, inclusive os votos afirmativos de todos os membros permanentes, ficando estabelecido que, nas decisões previstas no Capítulo VI e no parágrafo 3 do artigo 52, aquele que for parte em uma controvérsia se absterá de votar." (SALIBA, 2008, p. 719-720)

Já no capítulo VII da Carta das Nações Unidas, estão previstas as ações para casos de ruptura da paz e de atos de agressão (SALIBA, 2008, p. 719-724). De acordo com os procedimentos da Carta, em primeiro lugar, o Conselho de Segurança deve procurar esgotar as vias pacíficas de resolução de controvérsias. Somente caso essas vias sejam esgotadas e o problema permaneça é que as possibilidades de utilização de medidas do capítulo VII poderiam ser aplicadas. Essa ideia pode ser depreendida não só por conta do artigo 33 dentro do capítulo VI especificamente, mas também por meio da compreensão dos princípios e propósitos da organização contidos nos artigos 1 e 2 (SALIBA, 2008, 715-716).

É importante esclarecer que normalmente quando se fala de uma resolução baseada no capítulo VII, há uma indicação de resolução tendente à permissão do uso da força. Sendo este capítulo o responsável pelo procedimento que pode culminar na decisão de utilizar o uso da força contra um Estado, resoluções e missões baseadas no capítulo VII são tipicamente aquelas com algum poder a mais que não somente de observar, seja ele de criar um safe haven ou proteger civis, por exemplo. Por isso, apesar de já existir uma missão baseada no capítulo VII em Carana, o rumor de o membro permanente vetar resoluções baseadas no capítulo VII deve ser interpretado no sentido de vetar qualquer resolução que atribua ações ou poderio militar ativo a uma missão.

Portanto, nota-se que, para o caso de Carana apontado, a conduta mais apropriada para o Conselho de Segurança da ONU seria de condenar os acontecimentos e iniciar, caso seja considerado necessário, os embargos e os bloqueios próprios, como, por exemplo, bloqueios de armas ou econômicos para a região. Tendo em vista que Carana já possui uma missão do Conselho de Segurança fundamentada no capítulo VII, seria por bem utilizar a missão existente e reforça-la para tentar ajudar na resolução pacífica do conflito.

A praxe desta situação é que a missão seja reforçada na sua segurança e aja de maneira mais defensiva preservando pelo seu staff. Devido às mortes, é evidente que a distribuição de civis e militares em Carana terá de ser menor de forma a tentar assegurar a vida da equipe. Não só por conta da morte de pessoas da equipe, mas até mesmo por conta das disputas que se tornaram mais intensas, o agrupamento da missão é vital para que esta possa ser continuada. Como já é previsto na missão, a respeito do apoioàimplementaçãodeumcessarfogo,noitem(f), "protegeropessoaldasNações Unidas”, dever- 
se-á priorizar esta função sem negligenciar o final que permite "proteger civis sob ameaça iminente de violência física, dentro de suas capacidades" (Resolução $\left.\mathrm{n}^{\circ} 1.844,2009\right)$. Essa previsão demonstra que não há uma preocupação com os civis locais, mas que, com um membro permanente ameaçando vetar qualquer ação mais incisiva, qualquer medida além do que já foi previsto é muito difícil de ser aprovada no Conselho.

Pelo fato de o acordo de paz (KPA) ter sido completamente violado e desconsiderado, outra importante função da missão seria no sentido de revitalizar o acordo anterior ou incentivar a negociação de um novo acordo. Essa função não descaracterizaria uma função suplementar da missão de observar e monitorar se as partes estão seguindo as ordens do Conselho de Segurança ou não, e reportar o mais rápido possível, caso as resoluções do Conselho de Segurança não estejam sendo respeitadas e cumpridas.

A missão tem o dever-poder de auxiliar a defesa de civis dentro de suas capacidades. Contudo, essa capacidade é limitada, tendo em vista as áreas de atuação da missão, e considerando que este não é o objetivo principal da missão em si. Dessa forma, há uma preocupação ainda com relação à população em geral, pois existem acusações acerca de práticas genocidas no país.

A Convenção para a Prevenção e a Repressão do Crime de Genocídio faz parte dos tratados e convenções incluídos no sistema das Nações Unidas. A convenção confirma a classificação de genocídio como um crime perante o direito internacional, o qual deve ser combatido e punido como explicita o artigo $1^{\circ}$ da convenção: "Artigo I - As partes contratantes confirmam que o genocídio, quer cometido em tempo de paz, quer em tempo de guerra, é um crime contra o Direito Internacional, o qual elas se comprometem a prevenir e punir." (CEDIN, 2013, p. 2)

Porém, não existe qualquer previsão que especifique expressamente as possibilidades e medidas de prevenção efetiva. As ações que devem ser empreendidas precisam seguir os procedimentos da Carta da ONU. Assim, a prevenção acaba sendo sujeita aos procedimentos do Conselho de Segurança e, portanto, fica vulnerável a instabilidade política que o Conselho está sujeito.

Essa discussão ainda é bastante emblemática, pois o caso de Ruanda demonstrou uma ineficácia de resposta por parte da ONU e seu aparato em tentar prevenir ou agir de forma efetiva sob o genocídio ruandês. ${ }^{5}$ Um inquérito independente requerido pelo Secretário Geral

\footnotetext{
${ }^{5} \mathrm{O}$ caso de Ruanda teve uma repercussão muito grande para o sistema internacional, especialmente por conta de toda a divulgação que o caso teve. Existem vários filmes inclusive que tratam do genocídio ruandês. Para uma
} 
analisou as ações da ONU durante o genocídio de 1994 e diagnosticou "uma falta de interesse e de recursos a serem empregados para prevenir e parar o evento" (CARLSSON; SUNGJOO; KUPOLATI, 1999).

Além do caso ruandês, o massacre de Srebrenica também é muito conhecido pela ineficiência de resposta pelo Conselho de Segurança. No caso da Bósnia, a ação da ONU foi ineficiente, preocupando-se apenas em afirmar a existência de "áreas seguras" para os mulçumanos da região, mas não agindo realmente em prol da proteção e segurança deles. Mais de 8.000 pessoas foram mortas sem que houvesse uma plena e direta intenção de agir por parte do órgão. A situação abriu uma enorme margem de críticas à lentidão burocrática do processamento político para lidar com algo tão emergencial e impactante. ${ }^{6}$

Todo esse debate sobre intervenção, soberania e legitimidade para o uso da força, quando o Estado não cumpre o seu papel, deu espaço para uma melhor evolução do direito humanitário internacional, que é desenvolvido tanto institucionalmente dentro do Sistema das Nações Unidas, por meio de resoluções do próprio Conselho de Segurança, por exemplo, como fora dele com o avanço do debate humanitário no cenário internacional. Dentre as diversas formas de proteção de civis, é possível citar a "Responsabilidade de Proteger", por ser um exemplo de tese que ganhou repercussão por sua adoção pela Assembleia Geral da Organização das Nações Unidas.

Por conta das atribuições e do progresso das relações internacionais desde o fim da Segunda Guerra Mundial, cada vez mais a absoluta soberania do Estado vinha sendo colocada em dúvida. As convenções internacionais cada vez mais tinham conteúdo de obrigação daquilo que o Estado deveria fazer. O progresso dos direitos humanos no cenário internacional também ocorreu, não só com a Declaração Universal dos Direitos Humanos, mas também com outras convenções como a de Prevenção e Punição ao Genocídio, a Convenção Contra Tortura, entre outras.

Vale ressaltar, no entanto, que tendo em vista a necessidade de atuação do Estado para uma maior efetiva proteção dos civis, os entraves enfrentados por esses entes continuam a ser ainda um dos maiores obstáculos. Justamente, por isso, o debate sobre possíveis soluções e formas de gerir situações de conflito ainda é constantemente discutido no âmbito

leitura do caso feita pela própria ONU, ler: International Day of Reflection on the 1994 Genocide in Rwanda. 7 April 2004. Backgrounder. Disponívelem:

<http://www.un.org/events/rwanda/backgrounder.html>. Acesso em: 8/12/2013.

${ }^{6}$ O massacre de Srebrenica é bem conhecido pelos estudiosos das Relações Internacionais. Para uma melhor introdução sobre o caso, leia: ROHDE, David. An Introduction to Srebrenica. Disponível em: <http://www.srebrenica.org.uk/what-happened/srebrenica-genocide/introduction-srebrenica/>. Acesso em: 30/05/2017. 
internacional. Para fins ilustrativos, pode-se ver brevemente como exemplo a "Responsabilidade de Proteger".

De maneira resumida, o primeiro passo em direção à chamada Responsabilidade de Proteger (R2P) veio com o relatório final da Comissão Internacional sobre Intervenção e Soberania dos Estados, em que o termo foi oficialmente utilizado, e começou a moldar o que seria essa doutrina (ZIFCAK, 2010, p. 511-512). E foi confirmado pelo relatório do Painel de Alto Nível sobre Ameaças, Desafios e Mudanças realizado em 2004 (GRAY, 2008, p. 51-52). Em geral, a doutrina já prevê que todo Estado tem a responsabilidade de proteger os seus nacionais, sendo possível essa responsabilidade recair sobre a comunidade internacional, caso o Estado não cumpra com essa sua responsabilidade, sendo aquela da comunidade internacional paralela e subsidiária à do Estado em que ocorrerem os eventos. E que o Conselho de Segurança é o órgão mais qualificado para exercer essa competência de autorizar qualquer intervenção militar que venha a ser necessária.

Assim, mesmo que de forma breve, nesse caso, é possível verificar que se buscou uma saída jurídica que justificasse uma intervenção em ocasiões extremas. Mas essa saída ainda não transpassou todo o sistema para o uso da força que já existia, de forma que ainda existe uma dependência em relação a todo o procedimento de votação do Conselho de Segurança.

Em 2005, a Assembleia Geral da ONU, um de seus principais órgãos com importante função de ser um canal para a comunicação e o entendimento entre os Estados acerca de diversas agendas, definiu em um documento oficial da organização o que seria a Responsabilidade de Proteger. O "United Nations World Summit" estabelece essa responsabilidade do Estado:

\footnotetext{
"138. Each individual State has the responsibility to protect its populations from genocide, war crimes, ethnic cleansing and crimes against humanity. This responsibility entails the prevention of such crimes, including their incitement, through appropriate and necessary means. We accept that responsibility and will act in accordance with it. The international community should, as appropriate, encourage and help States to exercise this responsibility and support the United Nations in establishing an early warning capability. "(World Summit Outcome, 2005)
}

A Assembleia Geral concretizou ainda mais a ideia de que um Estado não está completamente imune a tudo aquilo que ele faz no âmbito de sua soberania interna. A ONU também tem de ficar atenta para os crimes contra a humanidade, de genocídio, de guerra e de limpeza étnica dentro dos países. Todavia, a Assembleia Geral é obrigada a seguir os 
procedimentos e a Carta das Nações Unidas como um todo. Dessa forma, na mesma publicação é explicitado:

\begin{abstract}
"139. The international community, through the United Nations, also has the responsibility to use appropriate diplomatic, humanitarian and other peaceful means, in accordance with Chapters VI and VIII of the Charter, to help to protect populations from genocide, war crimes, ethnic cleansing and crimes against humanity. In this context, we are prepared to take collective action, in a timely and decisive manner, through the Security Council, in accordance with the Charter, including

Chapter VII, on a case-by-case basis and in cooperation with relevant regional organizations as appropriate, should peaceful means be inadequate and national authorities are manifestly failing to protect their populations from genocide, war crimes, ethnic cleansing and crimes against humanity."(World Summit Outcome, 2005)
\end{abstract}

Portanto, percebe-se que não há liberdade para o uso unilateral ou coletivo que não sejam aqueles já previstos na Carta. $^{7}$ Como explica Liliana Jubilut ${ }^{8}$, a Assembleia não tem a função de permitir ou não o uso da força, sendo a sua legitimidade e função advindas do mesmo tratado que limita o uso da força. Além disso, organizações locais ou regionais também estão submetidas ao aval do Conselho de Segurança para atuarem empregando o uso da força. ${ }^{9}$ Então, todo o debate de uso da força por um Estado para fins de auxílio fica dependendo de uma permissão do Conselho de Segurança, ou seja, dependendo da política e das negociações dentro do órgão.

Assim, no caso de um membro agir sem uma resolução do Conselho de Segurança, ele estará agindo fora dos limites legais do direito internacional público convencionado, pois, se ele não foi atacado e não foi evocado nenhum mecanismo de defesa em grupo, ele ainda se submete ao aval do Conselho de Segurança e, principalmente, dos demais membros permanentes.

\title{
Conclusão e Recomendações
}

\footnotetext{
7 Existem previsões como o direito de legítima defesa do Estado, previsto no art. 51 da Carta, mas mesmo esses direitos são descritos como cabíveis até que o Conselho de Segurança tenha tomado as medidas necessárias para manutenção da paz e da segurança, ou seja, a ação do Conselho ainda deve ser priorizada, de acordo com o tratado. Como em nenhum momento há indicação no caso, de que o membro permanente que ameaça usar a força foi atacado, não seria o caso da evocação desse artigo de qualquer maneira.

${ }^{8}$ Para demais investigações sobre manifestações da Assembleia, leia: JUBILUT, Liliana Lyra. A "Responsabilidade de Proteger" é uma mudança real para as intervenções humanitárias?. Centro de Direito Internacional - cedin. Revista Eletrônica de Direito Internacional. Disponível em:

<http://www.cedin.com.br/revistaeletronica/artigos/Liliana\%20Jubilut\%20DIH.pdf>. Acesso em: 8/12/2013.

9 E não há indícios no caso de que haja uma organização regional com intenção de atuar de modo intervencionista em Carana.
} 
É necessário entender que a situação em Carana é bastante complexa e consideravelmente urgente. A situação do país antes mesmo dos incidentes recentes já era alarmante o suficiente para uma missão baseada no capítulo VII estar em vigor no território do Estado. Existem fortes considerações, como foi apontado no trabalho, de que o caso deve ser investigado urgentemente pela ONU, a qual deveria mostrar efetividade e empenho em atuar.

Uma das recomendações ao caso seria a tentativa de revitalizar a missão atual UNAC - fazendo com que ela auxilie em uma negociação para um acordo de paz entre as partes. Caso a condenação dos últimos acontecimentos não seja uma pressão suficiente para um acordo na região, a proposta de uma medida um pouco mais incisiva seria adequada.

Nota-se que qualquer ação mais intervencionista será bastante difícil de passar pelo Conselho de Segurança, pois já existe um membro alegando que vetará autorizações baseadas no capítulo VII. Contudo, tendo em vista que os acontecimentos são bastante graves, ocorrendo inclusive a invasão de territórios, a proposta de iniciar embargos contra os países envolvidos mostra que a ONU está se preocupando por um lado, mas não está tomando medidas radicais por outro lado, sendo mais provável uma colaboração deste país que ameaça vetar qualquer autorização do capítulo VII, logo, mais provável de ser bem sucedida em conseguir efetivamente uma resolução aprovada pelo órgão.

A análise demonstrou que, atuando dentro das previsões legais internacionais, a comunidade internacional só pode efetivamente auxiliar Carana se uma resolução do Conselho de Segurança da ONU autorizar. Já existem teses, como a Responsabilidade de Proteger, que aumentam o espectro de fundamentações possíveis para uma atuação da ONU mais efetiva. Entretanto, atuando dentro do direito internacional, o quadro mais apropriado continua sendo por meio de uma resolução do Conselho de Segurança, ficando o caso sujeito à política e à negociação principalmente dos membros permanentes do conselho que tem poder

de veto. 


\section{Referências Bibliográficas}

ALEXY, Robert. Theorie der Grundrechte. Baden: Nomos, 1985, pág. 75. apud. CANOTILHO, J. J. Gomes. Direito Constitucional e Teoria da Constituição. $2^{a}$ ed. Coimbra: Livraria Almedina, 1998.

BROWN, Chris; AINLEY, Kirsten.Understanding International Relations. $4^{\mathrm{a}}$ ed. New York: Palgrave Macmillan, 2009.

BROWNLIE, Ian. Principles of Public International Law. $7^{\text {a }}$ ed. New York: Oxford University Press Inc., 2008.

ÇALI, Başak. International Law for International Relations. New York: OxfordUniversity Press Inc., 2010.

CARLSSON, Ingvar. SUNG-JOO, Han. KUPOLATI, Rufus M. Report of the Independent Inquiry into the actions of the United Nations during the 1994 genocide in Rwanda. 15 December 1999. Disponível em: <http://daccess-ddsny.un.org/doc/UNDOC/GEN/N99/395/47/IMG/N9939547.pdf?OpenElement>. Acesso em: 8/12/2013.

Centro de Direito Internacional - Cedin. Convenção para a Prevenção e a Repressão do Crime de Genocídio. Disponível em: 〈http://www.oas.org〉. Acesso em: 7/12/2013.

Conselho de Segurança. Organização das Nações Unidas. Resolução nº 1.844 (2009). Mimeografado. [Fictícia].

DELGADO, Vladimir Chaves. A Soberania dos Estados Face a Questão de Ingerência Humanitária no Direito Internacional Público. Rev. Jur., Brasília, v. 7, n. 76, p. 61-69, dez/2005 a jan/2006. Disponível em:

$<$ http://www.planalto.gov.br/ccivil_03/revista/rev_76/artigos/PDF/VladimirChaves_Re v76.pdf>.Acessoem: 8/12/2013.

GRAY, Christine. International Law and the Use of Force. 3rd Ed. Nova York: Oxford University Press, 2008. 
Institute for International Law and Justice. New York University School of Law.The Corfu Channel Case.(United Kingdom v. Albania). ICJ Decision 9 April 1949. Disponível em:

〈http://www.iilj.org/courses/documents/corfuchannel.unitedkingdomv.albania.pdf $>$. Acesso em: 7/12/2013.

International Court of Justice. Press Release. 1949. Disponível em: <http://www.icjcij.org/docket/files/1/11885.pdf>. Acesso em: 30/05/2017.

International Day of Reflection on the 1994 Genocide in Rwanda.7 April 2004. Backgrounder. Disponível em:

<http://www.un.org/events/rwanda/backgrounder.html>. Acesso em: 8/12/2013.

JUBILUT, Liliana Lyra. A "Responsabilidade de Proteger" é uma mudança real para as intervenções humanitárias?. Centro de Direito Internacional - cedin. Revista Eletrônica de Direito Internacional. Disponível em:

$\langle$ http://www.cedin.com.br/revistaeletronica/artigos/Liliana\%20Jubilut\%20DIH.pdf $>$. Acesso em: 8/12/2013.

MAZZUOLI, Valerio de Oliveira. Curso de Direito Internacional Público. $5^{\mathrm{a}}$ ed. São Paulo: EditoraRevista dos Tribunais, 2011.

Military and Paramilitary Activities in and against Nicaragua (Nicaragua v. United States of America). Merits, Judgment. I.C.J. Reports 1986, p. 95. Disponível em: <http://www.icj-cij.org/docket/files/70/6503.pdf $>$. Acesso em: 7/12/2013.

ROHDE, David. An Introduction to Srebrenica.Disponível em: <http://www.srebrenica.org.uk/what-happened/srebrenica-genocide/introductionsrebrenica/>. Acesso em: 30/05/2017.

SALIBA, Aziz Tuffi. Legislação de direito internacional. $3^{\mathrm{a}}$ ed. São Paulo: Rideel, 2008 Statute of the International Court of Justice. Article 38, p. 26. Disponível em: $\langle$ http://legal.un.org/avl/pdf/ha/sicj/icj_statute_e.pdf $>$. Acesso em: 5/12/2013. 
THIRLWAY, Hugh. The Sources of International Law. In: EVANS, Malcolm D. International Law. $3^{\text {a }}$ ed. New York: Oxford University Press Inc., 2010, p. 95-121.

World Summit Outcome. General Assembly. United Nations. Sixtieth session. 2005. Disponívelem:

<http://www.un.org/en/preventgenocide/adviser/pdf/World\%20Summit\%20Outcome \% 20Document.pdf\#page=30>. Acesso em: 8/12/2013.

ZIFCAK, Spencer. The Responsibility to Protect. In: EVANS, Malcolm D.

International Law. $3^{a}$ ed. New York: Oxford University Press Inc., 2010, p. 504-527. 